\title{
Some coupled fixed-point theorems in two quasi-partial metric spaces
}

Feng $\mathrm{Gu}^{1}$ and Lin Wang ${ }^{2 *}$

\section{"Correspondence:}

WL64mail@aliyun.com

${ }^{2}$ College of Statistics and

Mathematics, Yunnan University of

Finance and Economics, Kunming, Yunnan 650221, China

Full list of author information is available at the end of the article

\begin{abstract}
The purpose of this paper is to prove some new coupled common fixed-point theorems for mappings defined on a set equipped with two quasi-partial metrics. We also provide illustrative examples in support of our new results.
\end{abstract}

MSC: $47 \mathrm{H} 10 ; 54 \mathrm{H} 25$

Keywords: common coupled fixed point; coupled coincidence point; $w$-compatible mapping pairs; quasi-partial metric space

\section{Introduction and preliminaries}

In 1994, Matthews [1] introduced the notion of partial metric spaces as follows.

Definition 1.1 [1] A partial metric on a nonempty set $X$ is a function $p: X \times X \rightarrow \mathbb{R}^{+}$ such that for all $x, y, z \in X$ :

(p1) $x=y \Leftrightarrow p(x, x)=p(x, y)=p(y, y)$,

(p2) $p(x, x) \leq p(x, y)$

(p3) $p(x, y)=p(y, x)$,

(p4) $p(x, y) \leq p(x, z)+p(z, y)-p(z, z)$.

A partial metric space is a pair $(X, p)$ such that $X$ is a nonempty set and $p$ is a partial metric on $X$.

In [1], Matthews extended the Banach contraction principle from metric spaces to partial metric spaces. Based on the notion of partial metric spaces, several authors (for example, [2-32]) obtained some fixed-point results for mappings satisfying different contractive conditions. Very recently, Haghi et al. [33] showed in their interesting paper that some fixed-point theorems in partial metric spaces can be obtained from metric spaces.

Karapinar et al. [34] introduced the concept of quasi-partial metric spaces and studied some fixed-point problems on quasi-partial metric spaces. The notion of a quasi-partial metric space is defined as follows.

Definition 1.2 [34] A quasi-partial metric on nonempty set $X$ is a function $q: X \times X \rightarrow$ $\mathbb{R}^{+}$which satisfies:

$\left(\mathrm{QPM}_{1}\right)$ If $q(x, x)=q(x, y)=q(y, y)$, then $x=y$,

$\left(\mathrm{QPM}_{2}\right) q(x, x) \leq q(x, y)$,

(2014 Gu and Wang: licensee Springer. This is an Open Access article distributed under the terms of the Creative Commons Attribution License (http://creativecommons.org/licenses/by/2.0), which permits unrestricted use, distribution, and reproduction in any medium, provided the original work is properly cited. 
$\left(\mathrm{QPM}_{3}\right) q(x, x) \leq q(y, x)$, and

$\left(\mathrm{QPM}_{4}\right) q(x, y)+q(z, z) \leq q(x, z)+q(z, y)$

for all $x, y, z \in X$.

A quasi-partial metric space is a pair $(X, q)$ such that $X$ is a nonempty set and $q$ is a quasi-partial metric on $X$.

Let $q$ be a quasi-partial metric on set $X$. Then

$$
d_{q}(x, y)=q(x, y)+q(y, x)-q(x, x)-q(y, y)
$$

is a metric on $X$.

Definition 1.3 [34] Let $(X, q)$ be a quasi-partial metric space. Then

(i) A sequence $\left\{x_{n}\right\}$ converges to a point $x \in X$ if and only if

$$
q(x, x)=\lim _{n \rightarrow \infty} q\left(x, x_{n}\right)=\lim _{n \rightarrow \infty} q\left(x_{n}, x\right)
$$

(ii) A sequence $\left\{x_{n}\right\}$ is called a Cauchy sequence if $\lim _{n, m \rightarrow \infty} q\left(x_{n}, x_{m}\right)$ and $\lim _{n, m \rightarrow \infty} q\left(x_{m}, x_{n}\right)$ exist (and are finite).

(iii) The quasi-partial metric space $(X, q)$ is said to be complete if every Cauchy sequence $\left\{x_{n}\right\}$ in $X$ converges, with respect to $\tau_{q}$, to a point $x \in X$ such that

$$
q(x, x)=\lim _{n, m \rightarrow \infty} q\left(x_{n}, x_{m}\right)=\lim _{n, m \rightarrow \infty} q\left(x_{n}, x_{m}\right) .
$$

Bhaskar and Lakshmikantham [35] introduced the concept of a coupled fixed point and studied some nice coupled fixed-point theorems. Later, Lakshmikantham and Ćirić [36] introduced the notion of a coupled coincidence point of mappings. For some works on a coupled fixed point, we refer the reader to [37-62].

Definition 1.4 [35] Let $X$ be a nonempty set. We call an element $(x, y) \in X \times X$ a coupled fixed point of the mapping $F: X \times X \rightarrow X$ if $F(x, y)=x$ and $F(y, x)=y$.

Definition 1.5 [36] An element $(x, y) \in X \times X$ is called

(i) a coupled coincidence point of the mapping $F: X \times X \rightarrow X$ and $g: X \rightarrow X$ if $F(x, y)=g x$ and $F(y, x)=g y$; in this case $(g x, g y)$ is called coupled point of coincidence of mappings $F$ and $g$;

(ii) a common coupled fixed point of mappings $F: X \times X \rightarrow X$ and $g: X \rightarrow X$ if $F(x, y)=g x=x$ and $F(y, x)=g y=y$;

(iii) a common coupled fixed point of mappings $F: X \times X \rightarrow X$ and $g: X \rightarrow X$ if $F(x, y)=g x=x$ and $F(y, x)=g y=y$.

Abbas et al. [37] introduced the concept of $w$-compatible mappings as follows.

Definition 1.6 [37] Let $X$ be a nonempty set. We say that the mappings $F: X \times X \rightarrow X$ and $g: X \rightarrow X$ are $w$-compatible if $g F(x, y)=F(g x, g y)$ whenever $g x=F(x, y)$ and $g y=F(y, x)$. 
Very recently, Shatanawi and Pitea [38] obtained some common coupled fixed-point results for a pair of mappings in quasi-partial metric space.

Theorem 1.1 (see [38, Theorem 2.1]) Let $(X, q)$ be a quasi-partial metric space, $g: X \rightarrow X$ and $F: X \times X \rightarrow X$ be two mappings. Suppose that there exist $k_{1}, k_{2}$, and $k_{3}$ in $[0,1)$ with $k_{1}+k_{2}+k_{3}<1$ such that the condition

$$
\begin{aligned}
& q(F(x, y), F(u, v))+q(F(y, x), F(v, u)) \\
& \quad \leq k_{1}[q(g x, g u)+q(g y, g v)]+k_{2}[q(g x, F(x, y))+q(g y, F(y, x))] \\
& \quad+k_{3}[q(g u, F(u, v))+q(g v, F(v, u))]
\end{aligned}
$$

holds for all $x, y, u, v \in X$. Also, suppose we have the following hypotheses:

(i) $F(X \times X) \subset g(X)$.

(ii) $g(X)$ is a complete subspace of $X$ with respect to the quasi-partial metric $q$.

Then the mappings $F$ and $g$ have a coincidence point $(x, y)$ satisfying $g x=F(x, y)$ and $g y=$ $F(y, x)$.

Moreover, if $F$ and $g$ are $w$-compatible, then $F$ and $g$ have a unique common coupled fixed point of the form $(x, x)$.

The aim of this article is to prove some new coupled common fixed-point theorems for mappings defined on a set equipped with two quasi-partial metrics.

The following lemma is crucial in our work.

Lemma 1.1 [38] Let $(X, q)$ be a quasi-partial metric space. Then the following statements hold true:

(i) If $q(x, y)=0$, then $x=y$.

(ii) If $x \neq y$, then $q(x, y)>0$ and $q(y, x)>0$.

In this manuscript, we generalize, improve, enrich, and extend the above coupled common fixed-point results. We also state some examples to illustrate our results. This paper can be considered as a continuation of the remarkable works of Aydi [12], Karapınar et al. [34], and Shatanawi and Pitea [38].

\section{Main results}

Now we shall prove our main results.

Theorem 2.1 Let $q_{1}$ and $q_{2}$ be two quasi-metrics on $X$ such that $q_{2}(x, y) \leq q_{1}(x, y)$, for all $x, y \in X$, and let $F: X \times X \rightarrow X, g: X \rightarrow X$ be two mappings. Suppose that there exist $k_{1}$, $k_{2}, k_{3}, k_{4}$, and $k_{5}$ in $[0,1)$ with

$$
k_{1}+k_{2}+k_{3}+2 k_{4}+k_{5}<1
$$

such that the condition

$$
\begin{aligned}
& q_{1}(F(x, y), F(u, v))+q_{1}(F(y, x), F(v, u)) \\
& \quad \leq k_{1}\left[q_{2}(g x, g u)+q_{2}(g y, g v)\right]+k_{2}\left[q_{2}(g x, F(x, y))+q_{2}(g y, F(y, x))\right]
\end{aligned}
$$




$$
\begin{aligned}
& +k_{3}\left[q_{2}(g u, F(u, v))+q_{2}(g v, F(v, u))\right]+k_{4}\left[q_{2}(g x, F(u, v))+q_{2}(g y, F(v, u))\right] \\
& +k_{5}\left[q_{2}(g u, F(x, y))+q_{2}(g v, F(y, x))\right]
\end{aligned}
$$

holds for all $x, y, u, v \in X$. Also, suppose we have the following hypotheses:

(i) $F(X \times X) \subset g(X)$.

(ii) $g(X)$ is a complete subspace of $X$ with respect to the quasi-partial metric $q_{1}$.

Then the mappings $F$ and $g$ have a coincidence point $(x, y)$ satisfying $g x=F(x, y)=F(y, x)=$ gy.

Moreover, if $F$ and $g$ are $w$-compatible, then $F$ and $g$ have a unique common coupled fixed point of the form $(u, u)$.

Proof Let $x_{0}, y_{0} \in X$. Since $F(X \times X) \subset g(X)$, we can choose $x_{1}, y_{1} \in X$ such that $g x_{1}=$ $F\left(x_{0}, y_{0}\right)$ and $g y_{1}=F\left(y_{0}, x_{0}\right)$. Similarly, we can choose $x_{2}, y_{2} \in X$ such that $g x_{2}=F\left(x_{1}, y_{1}\right)$ and $g y_{2}=F\left(y_{1}, x_{1}\right)$. Continuing in this way we construct two sequences $\left\{x_{n}\right\}$ and $\left\{y_{n}\right\}$ in $X$ such that

$$
g x_{n+1}=F\left(x_{n}, y_{n}\right) \quad \text { and } \quad g y_{n+1}=F\left(y_{n}, x_{n}\right), \quad \forall n \geq 0 .
$$

It follows from (2.2) and $\left(\mathrm{QPM}_{4}\right)$ that

$$
\begin{aligned}
& q_{1}\left(g x_{n}, g x_{n+1}\right)+q_{1}\left(g y_{n}, g y_{n+1}\right) \\
&= q_{1}\left(F\left(x_{n-1}, y_{n-1}\right), F\left(x_{n}, y_{n}\right)\right)+q_{1}\left(F\left(y_{n-1}, x_{n-1}\right), F\left(y_{n}, x_{n}\right)\right) \\
& \leq k_{1}\left[q_{2}\left(g x_{n-1}, g x_{n}\right)+q_{2}\left(g y_{n-1}, g y_{n}\right)\right] \\
&+k_{2}\left[q_{2}\left(g x_{n-1}, F\left(x_{n-1}, y_{n-1}\right)+q_{2}\left(g y_{n-1}, F\left(y_{n-1}, x_{n-1}\right)\right)\right)\right] \\
&+k_{3}\left[q_{2}\left(g x_{n}, F\left(x_{n}, y_{n}\right)\right)+q_{2}\left(g y_{n}, F\left(y_{n}, x_{n}\right)\right)\right] \\
&+k_{4}\left[q_{2}\left(g x_{n-1}, F\left(x_{n}, y_{n}\right)\right)+q_{2}\left(g y_{n-1}, F\left(y_{n}, x_{n}\right)\right)\right] \\
&+k_{5}\left[q_{2}\left(g x_{n}, F\left(x_{n-1}, y_{n-1}\right)\right)+q_{2}\left(g y_{n}, F\left(y_{n-1}, x_{n-1}\right)\right)\right] \\
&=\left(k_{1}+k_{2}\right)\left[q_{2}\left(g x_{n-1}, g x_{n}\right)+q_{2}\left(g y_{n-1}, g y_{n}\right)\right]+k_{3}\left[q_{2}\left(g x_{n}, g x_{n+1}\right)+q_{2}\left(g y_{n}, g y_{n+1}\right)\right] \\
&+k_{4}\left[q_{2}\left(g x_{n-1}, g x_{n+1}\right)+q_{2}\left(g y_{n-1}, g y_{n+1}\right)\right]+k_{5}\left[q_{2}\left(g x_{n}, g x_{n}\right)+q_{2}\left(g y_{n}, g y_{n}\right)\right] \\
& \leq\left(k_{1}+k_{2}\right)\left[q_{2}\left(g x_{n-1}, g x_{n}\right)+q_{2}\left(g y_{n-1}, g y_{n}\right)\right]+k_{3}\left[q_{2}\left(g x_{n}, g x_{n+1}\right)+q_{2}\left(g y_{n}, g y_{n+1}\right)\right] \\
&+k_{4}\left[q_{2}\left(g x_{n-1}, g x_{n}\right)+q_{2}\left(g x_{n}, g x_{n+1}\right)-q_{2}\left(g x_{n}, g x_{n}\right)+q_{2}\left(g y_{n-1}, g y_{n}\right)+q_{2}\left(g y_{n}, g y_{n+1}\right)\right. \\
&\left.-q_{2}\left(g y_{n}, g y_{n}\right)\right]+k_{5}\left[q_{2}\left(g x_{n}, g x_{n+1}\right)+q_{2}\left(g y_{n}, g y_{n+1}\right)\right] \\
& \leq\left(k_{1}+k_{2}+k_{4}\right)\left[q_{2}\left(g x_{n-1}, g x_{n}\right)+q_{2}\left(g y_{n-1}, g y_{n}\right)\right] \\
&+\left(k_{3}+k_{4}+k_{5}\right)\left[q 2\left(g x_{n}, g x_{n+1}\right)+q_{2}\left(g y_{n}, g y_{n+1}\right)\right] \\
& \leq\left(k_{1}+k_{2}+k_{4}\right)\left[q_{1}\left(g x_{n-1}, g x_{n}\right)+q_{1}\left(g y_{n-1}, g y_{n}\right)\right] \\
&+\left(k_{3}+k_{4}+k_{5}\right)\left[q_{1}\left(g x_{n}, g x_{n+1}\right)+q_{1}\left(g y_{n}, g y_{n+1}\right)\right],
\end{aligned}
$$


which implies that

$$
q_{1}\left(g x_{n}, g x_{n+1}\right)+q_{1}\left(g y_{n}, g y_{n+1}\right) \leq \frac{k_{1}+k_{2}+k_{4}}{1-k_{3}-k_{4}-k_{5}}\left[q_{1}\left(g x_{n-1}, g x_{n}\right)+q_{1}\left(g y_{n-1}, g y_{n}\right)\right] .
$$

Put $k=\frac{k_{1}+k_{2}+k_{4}}{1-k_{3}-k_{4}-k_{5}}$. Obviously, $0 \leq k<1$. By repetition of the above inequality (2.4) $n$ times, we get

$$
q_{1}\left(g x_{n}, g x_{n+1}\right)+q_{1}\left(g y_{n}, g y_{n+1}\right) \leq k^{n}\left[q_{1}\left(g x_{0}, g x_{1}\right)+q_{1}\left(g y_{0}, g y_{1}\right)\right] .
$$

Next, we shall prove that $\left\{g x_{n}\right\}$ and $\left\{g y_{n}\right\}$ are Cauchy sequences in $g(X)$.

In fact, for each $n, m \in \mathbb{N}, m>n$, from $\left(\mathrm{QPM}_{4}\right)$ and (2.5) we have

$$
\begin{aligned}
q_{1}\left(g x_{n}, g x_{m}\right)+q_{1}\left(g y_{n}, g y_{m}\right) & \leq \sum_{i=n}^{m-1}\left[q_{1}\left(g x_{i}, g x_{i+1}\right)+q_{1}\left(g y_{i}, g y_{i+1}\right)\right] \\
& \leq \sum_{i=n}^{m-1} k^{i}\left[q_{1}\left(g x_{0}, g x_{1}\right)+q_{1}\left(g y_{0}, g y_{1}\right)\right] \\
& \leq \frac{k^{n}}{1-k}\left[q_{1}\left(g x_{0}, g x_{1}\right)+q_{1}\left(g y_{0}, g y_{1}\right)\right] .
\end{aligned}
$$

This implies that

$$
\lim _{n, m \rightarrow \infty}\left[q_{1}\left(g x_{n}, g x_{m}\right)+q_{1}\left(g y_{n}, g y_{m}\right)\right]=0
$$

and so

$$
\lim _{n, m \rightarrow \infty} q_{1}\left(g x_{n}, g x_{m}\right)=0 \text { and } \lim _{n, m \rightarrow \infty} q_{1}\left(g y_{n}, g y_{m}\right)=0 .
$$

By similar arguments as above, we can show that

$$
\lim _{n, m \rightarrow \infty} q_{1}\left(g x_{m}, g x_{n}\right)=0 \quad \text { and } \quad \lim _{n, m \rightarrow \infty} q_{1}\left(g y_{m}, g y_{n}\right)=0 .
$$

Hence $\left\{g x_{n}\right\}$ and $\left\{g y_{n}\right\}$ are Cauchy sequences in $\left(g X, q_{1}\right)$. Since $\left(g X, q_{1}\right)$ is complete, there exist $g x, g y \in g(X)$ such that $\left\{g x_{n}\right\}$ and $\left\{g y_{n}\right\}$ converge to $g x$ and $g y$ with respect to $\tau_{q_{1}}$, that is,

$$
\begin{aligned}
q_{1}(g x, g x) & =\lim _{n \rightarrow \infty} q_{1}\left(g x, g x_{n}\right)=\lim _{n \rightarrow \infty} q_{1}\left(g x_{n}, g x\right) \\
& =\lim _{n, m \rightarrow \infty} q_{1}\left(g x_{m}, g x_{n}\right)=\lim _{n, m \rightarrow \infty} q_{1}\left(g x_{n}, g x_{m}\right)
\end{aligned}
$$

and

$$
\begin{aligned}
q_{1}(g y, g y) & =\lim _{n \rightarrow \infty} q_{1}\left(g y, g y_{n}\right)=\lim _{n \rightarrow \infty} q_{1}\left(g y_{n}, g y\right) \\
& =\lim _{n, m \rightarrow \infty} q_{1}\left(g y_{m}, g y_{n}\right)=\lim _{n, m \rightarrow \infty} q_{1}\left(g y_{n}, g y_{m}\right) .
\end{aligned}
$$


Combining (2.7)-(2.10), we have

$$
\begin{aligned}
q_{1}(g x, g x) & =\lim _{n \rightarrow \infty} q_{1}\left(g x, g x_{n}\right)=\lim _{n \rightarrow \infty} q_{1}\left(g x_{n}, g x\right) \\
& =\lim _{n, m \rightarrow \infty} q_{1}\left(g x_{m}, g x_{n}\right)=\lim _{n, m \rightarrow \infty} q_{1}\left(g x_{n}, g x_{m}\right)=0
\end{aligned}
$$

and

$$
\begin{aligned}
q_{1}(g y, g y) & =\lim _{n \rightarrow \infty} q_{1}\left(g y, g y_{n}\right)=\lim _{n \rightarrow \infty} q_{1}\left(g y_{n}, g y\right) \\
& =\lim _{n, m \rightarrow \infty} q_{1}\left(g y_{m}, g y_{n}\right)=\lim _{n, m \rightarrow \infty} q_{1}\left(g y_{n}, g y_{m}\right)=0 .
\end{aligned}
$$

By $\left(\mathrm{QPM}_{4}\right)$ we obtain

$$
\begin{aligned}
q_{1}\left(g x_{n+1}, F(x, y)\right) & \leq q_{1}\left(g x_{n+1}, g x\right)+q_{1}(g x, F(x, y))-q_{1}(g x, g x) \\
& \leq q_{1}\left(g x_{n+1}, g x\right)+q_{1}(g x, F(x, y)) \\
& \leq q_{1}\left(g x_{n+1}, g x\right)+q_{1}\left(g x, g x_{n+1}\right)+q_{1}\left(g x_{n+1}, F(x, y)\right)-q_{1}\left(g x_{n+1}, g x_{n+1}\right) \\
& \leq q_{1}\left(g x_{n+1}, g x\right)+q_{1}\left(g x, g x_{n+1}\right)+q_{1}\left(g x_{n+1}, F(x, y)\right) .
\end{aligned}
$$

Letting $n \rightarrow \infty$ in the above inequalities and using (2.11), we have

$$
\lim _{n \rightarrow \infty} q_{1}\left(g x_{n+1}, F(x, y)\right) \leq q_{1}(g x, F(x, y)) \leq \lim _{n \rightarrow \infty} q_{1}\left(g x_{n+1}, F(x, y)\right) .
$$

That is,

$$
\lim _{n \rightarrow \infty} q_{1}\left(g x_{n+1}, F(x, y)\right)=q_{1}(g x, F(x, y)) .
$$

Similarly, using (2.12) we have

$$
\lim _{n \rightarrow \infty} q_{1}\left(g y_{n+1}, F(y, x)\right)=q_{1}(g y, F(y, x)) .
$$

Now we prove that $F(x, y)=g x$ and $F(y, x)=g y$. In fact, it follows from (2.2) and (2.3) that

$$
\begin{aligned}
& q_{1}\left(g x_{n+1}, F(x, y)\right)+q_{1}\left(g y_{n+1}, F(y, x)\right) \\
&=q_{1}\left(F\left(x_{n}, y_{n}\right), F(x, y)\right)+q_{1}\left(F\left(y_{n}, x_{n}\right)\right) \\
& \leq k_{1}\left[q_{2}\left(g x_{n}, g x\right)+q_{2}\left(g y_{n}, g y\right)\right]+k_{2}\left[q_{2}\left(g x_{n}, F\left(x_{n}, y_{n}\right)\right)+q_{2}\left(g y_{n}, F\left(y_{n}, x_{n}\right)\right)\right] \\
&+k_{3}\left[q_{2}(g x, F(x, y))+q_{2}(g y, F(y, x))\right]+k_{4}\left[q_{2}\left(g x_{n}, F(x, y)\right)+q_{2}\left(g y_{n}, F(y, x)\right)\right] \\
&+k_{5}\left[q_{2}\left(g x, F\left(x_{n}, y_{n}\right)\right)+q_{2}\left(g y, F\left(y_{n}, x_{n}\right)\right)\right] \\
&= k_{1}\left[q_{2}\left(g x_{n}, g x\right)+q_{2}\left(g y_{n}, g y\right)\right]+k_{2}\left[q_{2}\left(g x_{n}, g x_{n+1}\right)+q_{2}\left(g y_{n}, g y_{n+1}\right)\right] \\
&+k_{3}\left[q_{2}(g x, F(x, y))+q_{2}(g y, F(y, x))\right]+k_{4}\left[q_{2}\left(g x_{n}, F(x, y)\right)+q_{2}\left(g y_{n}, F(y, x)\right)\right] \\
&+k_{5}\left[q_{2}\left(g x, g x_{n+1}\right)+q_{2}\left(g y, g y_{n+1}\right)\right] \\
& \leq k_{1}\left[q_{1}\left(g x_{n}, g x\right)+q_{1}\left(g y_{n}, g y\right)\right]+k_{2}\left[q_{1}\left(g x_{n}, g x_{n+1}\right)+q_{1}\left(g y_{n}, g y_{n+1}\right)\right]
\end{aligned}
$$




$$
\begin{aligned}
& +k_{3}\left[q_{1}(g x, F(x, y))+q_{1}(g y, F(y, x))\right]+k_{4}\left[q_{1}\left(g x_{n}, F(x, y)\right)+q_{1}\left(g y_{n}, F(y, x)\right)\right] \\
& +k_{5}\left[q_{1}\left(g x, g x_{n+1}\right)+q_{1}\left(g y, g y_{n+1}\right)\right] .
\end{aligned}
$$

Letting $n \rightarrow \infty$ in the above inequality, using (2.11)-(2.14), we obtain

$$
q_{1}(g x, F(x, y))+q_{1}(g y, F(y, x)) \leq\left(k_{3}+k_{4}\right)\left[q_{1}(g x, F(x, y))+q_{1}(g y, F(y, x))\right] .
$$

By (2.1) we have $k_{3}+k_{4}<1$. Hence, it follows from $(2.15)$ that $q_{1}(g x, F(x, y))=q_{1}(g y, F(y, x))=$ 0 . By Lemma 1.1, we get $F(x, y)=g x$ and $F(y, x)=g y$. Hence, $(g x, g y)$ is a coupled point of coincidence of mappings $F$ and $g$.

Next, we will show that the coupled point of coincidence is unique. Suppose that $\left(x^{*}, y^{*}\right) \in X \times X$ with $F\left(x^{*}, y^{*}\right)=g x^{*}$ and $F\left(y^{*}, x^{*}\right)=g y^{*}$. Using (2.2), (2.11), (2.12), and $\left(\mathrm{QPM}_{3}\right)$, we obtain

$$
\begin{aligned}
& q_{1}\left(g x, g x^{*}\right)+q_{1}\left(g y, g y^{*}\right) \\
&=q_{1}\left(F(x, y), F\left(x^{*}, y^{*}\right)\right)+q_{1}\left(F(y, x), F\left(y^{*}, x^{*}\right)\right) \\
& \leq k_{1}\left[q_{2}\left(g x, g x^{*}\right)+q_{2}\left(g y, g y^{*}\right)\right]+k_{2}\left[q_{2}(g x, F(x, y))+q_{2}(g y, F(y, x))\right] \\
&+k_{3}\left[q_{2}\left(g x^{*}, F\left(x^{*}, y^{*}\right)\right)+q_{2}\left(g y^{*}, F\left(y^{*}, x^{*}\right)\right)\right] \\
&+k_{4}\left[q_{2}\left(g x, F\left(x^{*}, y^{*}\right)\right)+q_{2}\left(g y, F\left(y^{*}, x^{*}\right)\right)\right] \\
&+k_{5}\left[q_{2}\left(g x^{*}, F(x, y)\right)+q_{2}\left(g y^{*}, F(y, x)\right)\right] \\
&= k_{1}\left[q_{2}\left(g x, g x^{*}\right)+q_{2}\left(g y, g y^{*}\right)\right]+k_{2}\left[q_{2}(g x, g x)+q_{2}(g y, g y)\right] \\
&+k_{3}\left[q_{2}\left(g x^{*}, g x^{*}\right)+q_{2}\left(g y^{*}, g y^{*}\right)\right]+k_{4}\left[q_{2}\left(g x, g x^{*}\right)+q_{2}\left(g y, g y^{*}\right)\right] \\
&+k_{5}\left[q_{2}\left(g x^{*}, g x\right)+q_{2}\left(g y^{*}, g y\right)\right] \\
& \leq\left(k_{1}+k_{4}\right)\left[q_{1}\left(g x, g x^{*}\right)+q_{1}\left(g y, g y^{*}\right)\right]+k_{2}\left[q_{1}(g x, g x)+q_{1}(g y, g y)\right] \\
&+k_{3}\left[q_{1}\left(g x^{*}, g x^{*}\right)+q_{1}\left(g y^{*}, g y^{*}\right)\right]+k_{5}\left[q_{1}\left(g x^{*}, g x\right)+q_{1}\left(g y^{*}, g y\right)\right] \\
& \leq\left(k_{1}+k_{3}+k_{4}\right)\left[q_{1}\left(g x, g x^{*}\right)+q_{1}\left(g y, g y^{*}\right)\right] \\
&+k_{5}\left[q_{1}\left(g x^{*}, g x\right)+q_{1}\left(g y^{*}, g y\right)\right] .
\end{aligned}
$$

This implies that

$$
q_{1}\left(g x, g x^{*}\right)+q_{1}\left(g y, g y^{*}\right) \leq \frac{k_{5}}{1-k_{1}-k_{3}-k_{4}} \cdot\left[q_{1}\left(g x^{*}, g x\right)+q_{1}\left(g y^{*}, g y\right)\right] .
$$

Similarly, we have

$$
q_{1}\left(g x^{*}, g x\right)+q_{1}\left(g y^{*}, g y\right) \leq \frac{k_{5}}{1-k_{1}-k_{3}-k_{4}} \cdot\left[q_{1}\left(g x, g x^{*}\right)+q_{1}\left(g y, g y^{*}\right)\right] .
$$

Substituting (2.17) into (2.16), we obtain

$$
q_{1}\left(g x, g x^{*}\right)+q_{1}\left(g y, g y^{*}\right) \leq\left(\frac{k_{5}}{1-k_{1}-k_{3}-k_{4}}\right)^{2} \cdot\left[q_{1}\left(g x, g x^{*}\right)+q_{1}\left(g y, g y^{*}\right)\right] .
$$


Since $\frac{k_{5}}{1-k_{1}-k_{3}-k_{4}}<1$, from (2.18), we must have $q_{1}\left(g x, g x^{*}\right)=q_{1}\left(g y, g y^{*}\right)=0$. By Lemma 1.1, we get $g x=g x^{*}$ and $g y=g y^{*}$, which implies the uniqueness of the coupled point of coincidence of $F$ and $g$, that is, $(g x, g y)$.

Next, we will show that $g x=g y$. In fact, from (2.2), (2.11), and (2.12) we have

$$
\begin{aligned}
& q_{1}(g x, g y)+q_{1}(g y, g x) \\
&= q_{1}(F(x, y), F(y, x))+q_{1}(F(y, x), F(x, y)) \\
& \leq k_{1}\left[q_{2}(g x, g y)+q_{2}(g y, g x)\right]+k_{2}\left[q_{2}(g x, F(x, y))+q_{2}(g y, F(y, x))\right] \\
&+k_{3}\left[q_{2}(g y, F(y, x))+q_{2}(g x, F(x, y))\right]+k_{4}\left[q_{2}(g x, F(y, x))+q_{2}(g y, F(x, y))\right] \\
&+k_{5}\left[q_{2}(g y, F(x, y))+q_{2}(g x, F(y, x))\right] \\
&= k_{1}\left[q_{2}(g x, g y)+q_{2}(g y, g x)\right]+k_{2}\left[q_{2}(g x, g x)+q_{2}(g y, g y)\right] \\
&+k_{3}\left[q_{2}(g y, g y)+q_{2}(g x, g x)\right]+k_{4}\left[q_{2}(g x, g y)+q_{2}(g y, g x)\right] \\
&+k_{5}\left[q_{2}(g y, g x)+q_{2}(g x, g y)\right] \\
& \leq k_{1}\left[q_{1}(g x, g y)+q_{1}(g y, g x)\right]+k_{2}\left[q_{1}(g x, g x)+q_{1}(g y, g y)\right] \\
&+k_{3}\left[q_{1}(g y, g y)+q_{1}(g x, g x)\right]+k_{4}\left[q_{1}(g x, g y)+q_{1}(g y, g x)\right] \\
&+k_{5}\left[q_{1}(g y, g x)+q_{1}(g x, g y)\right] \\
&=\left(k_{1}+k_{4}+k_{5}\right)\left[q_{1}(g x, g y)+q_{1}(g y, g x)\right] .
\end{aligned}
$$

Since $k_{1}+k_{4}+k_{5}<1$, we have $q_{1}(g x, g y)=q_{1}(g y, g x)=0$. By Lemma 1.1, we get $g x=g y$.

Finally, assume that $g$ and $F$ are $w$-compatible. Let $u=g x$, then we have $u=g x=F(x, y)=$ $g y=F(y, x)$, so that

$$
g u=g g x=g(F(x, y))=F(g x, g y)=F(u, u) .
$$

Consequently, $(u, u)$ is a coupled coincidence point of $F$ and $g$, and therefore $(g u, g u)$ is a coupled point of coincidence of $F$ and $g$, and by its uniqueness, we get $g u=g x$. Thus, we obtain $F(u, u)=g u=u$. Therefore, $(u, u)$ is the unique common coupled fixed point of $F$ and $g$. This completes the proof of Theorem 2.1.

In Theorem 2.1, if we take $q_{1}(x, y)=q_{2}(x, y)$ for all $x, y \in X$, then we get the following.

Corollary 2.1 Let $(X, q)$ be a quasi-partial metric space, $F: X \times X \rightarrow X$ and $g: X \rightarrow X$ be two mappings. Suppose that there exist $k_{1}, k_{2}, k_{3}, k_{4}$ and $k_{5}$ in $[0,1)$ with $k_{1}+k_{2}+k_{3}+2 k_{4}+$ $k_{5}<1$ such that the condition

$$
\begin{aligned}
& q(F(x, y), F(u, v))+q(F(y, x), F(v, u)) \\
& \leq k_{1}[q(g x, g u)+q(g y, g v)]+k_{2}[q(g x, F(x, y))+q(g y, F(y, x))] \\
&+k_{3}[q(g u, F(u, v))+q(g v, F(v, u))]+k_{4}[q(g x, F(u, v))+q(g y, F(v, u))] \\
&+k_{5}[q(g u, F(x, y))+q(g v, F(y, x))]
\end{aligned}
$$

holds for all $x, y, u, v \in X$. Also, suppose we have the following hypotheses: 
(i) $F(X \times X) \subset g(X)$.

(ii) $g(X)$ is a complete subspace of $X$ with respect to the quasi-partial metric $q$.

Then the mappings $F$ and $g$ have a coincidence point $(x, y)$ satisfying $g x=F(x, y)=F(y, x)=$ gy.

Moreover, if $F$ and $g$ are $w$-compatible, then $F$ and $g$ have a unique common coupled fixed point of the form $(u, u)$.

Remark 2.1 Corollary 2.1 improve and extend Theorem 2.1 of Shatanawi and Pitea [38]; the contractive condition defined by (1.1) is replaced by the new contractive condition defined by (2.23).

Corollary 2.2 Let $q_{1}$ and $q_{2}$ be two quasi-metrics on $X$ such that $q_{2}(x, y) \leq q_{1}(x, y)$, for all $x, y \in X$, and $F: X \times X \rightarrow X, g: X \rightarrow X$ be two mappings. Suppose that there exist $a_{i} \in[0,1)$ $(i=1,2,3, \ldots, 10)$ with

$$
a_{1}+a_{2}+a_{3}+a_{4}+a_{5}+a_{6}+2\left(a_{7}+a_{8}\right)+a_{9}+a_{10}<1
$$

such that the condition

$$
\begin{aligned}
& q_{1}(F(x, y), F(u, v)) \\
& \quad \leq a_{1} q_{2}(g x, g u)+a_{2} q_{2}(g y, g v)+a_{3} q_{2}(g x, F(x, y))+a_{4} q_{2}(g y, F(y, x)) \\
& \quad+a_{5} q_{2}(g u, F(u, v))+a_{6} q_{2}(g v, F(v, u))+a_{7} q_{2}(g x, F(u, v))+a_{8} q_{2}(g y, F(v, u)) \\
& \quad+a_{9} q_{2}(g u, F(x, y))+a_{10} q_{2}(g v, F(y, x))
\end{aligned}
$$

holds for all $x, y, u, v \in X$. Also, suppose we have the following hypotheses:

(i) $F(X \times X) \subset g(X)$.

(ii) $g(X)$ is a complete subspace of $X$ with respect to the quasi-partial metric $q_{1}$.

Then the mappings $F$ and $g$ have $a$ coincidence point $(x, y)$ satisfying $g x=F(x, y)=F(y, x)=$ gy.

Moreover, if $F$ and $g$ are $w$-compatible, then $F$ and $g$ have a unique common coupled fixed point of the form $(u, u)$.

Proof Given $x, y, u, v \in X$. It follows from (2.23) that

$$
\begin{aligned}
& q_{1}(F(x, y), F(u, v)) \\
& \quad \leq a_{1} q_{2}(g x, g u)+a_{2} q_{2}(g y, g v)+a_{3} q_{2}(g x, F(x, y))+a_{4} q_{2}(g y, F(y, x)) \\
& \quad+a_{5} q_{2}(g u, F(u, v))+a_{6} q_{2}(g v, F(v, u))+a_{7} q_{2}(g x, F(u, v))+a_{8} q_{2}(g y, F(v, u)) \\
& \quad+a_{9} q_{2}(g u, F(x, y))+a_{10} q_{2}(g v, F(y, x))
\end{aligned}
$$

and

$$
\begin{aligned}
& q_{1}(F(y, x), F(v, u)) \\
& \quad \leq a_{1} q_{2}(g y, g v)+a_{2} q_{2}(g x, g u)+a_{3} q_{2}(g y, F(y, x))+a_{4} q_{2}(g x, F(x, y))
\end{aligned}
$$




$$
\begin{aligned}
& +a_{5} q_{2}(g v, F(v, u))+a_{6} q_{2}(g u, F(u, v)) \\
& +a_{7} q_{2}(g y, F(v, u))+a_{8} q_{2}(g x, F(u, v)) \\
& +a_{9} q_{2}(g v, F(y, x))+a_{10} q_{2}(g u, F(x, y)) .
\end{aligned}
$$

Adding inequality (2.24) to inequality (2.25), we get

$$
\begin{aligned}
q_{1}\left(q_{1}(\right. & F(x, y), F(u, v))+F(y, x), F(v, u)) \\
\leq & \left(a_{1}+a_{2}\right)\left[q_{2}(g x, g u)+q_{2}(g y, g v)\right]+\left(a_{3}+a_{4}\right)\left[q_{2}(g x, F(x, y))+q_{2}(g y, F(y, x))\right] \\
& +\left(a_{5}+a_{6}\right)\left[q_{2}(g u, F(u, v))+q_{2}(g v, F(v, u))\right] \\
& +\left(a_{7}+a_{8}\right)\left[q_{2}(g x, F(u, v))+q_{2}(g y, F(v, u))\right] \\
& +\left(a_{9}+a_{10}\right)\left[q_{2}(g u, F(x, y))+q_{2}(g v, F(y, x))\right] .
\end{aligned}
$$

Therefore, the result follows from Theorem 2.1.

Remark 2.2 If we take $q_{1}(x, y)=q_{2}(x, y)$ for all $x, y \in X$ and $a_{7}=a_{8}=a_{9}=a_{10}=0$, then Corollary 2.2 is reduced to Corollary 2.1 of Shatanawi and Pitea [38].

Corollary 2.3 Let $q_{1}$ and $q_{2}$ be two quasi-metrics on $X$ such that $q_{2}(x, y) \leq q_{1}(x, y)$, for all $x, y \in X$, and $F: X \times X \rightarrow X, g: X \rightarrow X$ be two mappings. Suppose that there exists $k \in[0,1)$ such that the condition

$$
q_{1}(F(x, y), F(u, v))+q(F(y, x), F(v, u)) \leq k\left[q_{2}(g x, g u)+q_{2}(g y, g v)\right]
$$

holds for all $x, y, u, v \in X$. Also, suppose we have the following hypotheses:

(i) $F(X \times X) \subset g(X)$.

(ii) $g(X)$ is a complete subspace of $X$ with respect to the quasi-partial metric $q_{1}$.

Then the mappings $F$ and $g$ have a coincidence point $(x, y)$ satisfying $g x=F(x, y)=F(y, x)=$ gy.

Moreover, if $F$ and $g$ are $w$-compatible, then $F$ and $g$ have a unique common coupled fixed point of the form $(u, u)$.

Remark 2.3 If we take $q_{1}(x, y)=q_{2}(x, y)$ for all $x, y \in X$, then Corollary 2.3 is reduced to Corollary 2.2 of Shatanawi and Pitea [38].

Corollary 2.4 Let $q_{1}$ and $q_{2}$ be two quasi-metrics on $X$ such that $q_{2}(x, y) \leq q_{1}(x, y)$, for all $x, y \in X$, and $F: X \times X \rightarrow X, g: X \rightarrow X$ be two mappings. Suppose that there exists $k \in[0,1)$ such that the condition

$$
q_{1}(F(x, y), F(u, v))+q(F(y, x), F(v, u)) \leq k\left[q_{2}(g x, F(x, y))+q_{2}(g y, F(y, x))\right]
$$

holds for all $x, y, u, v \in X$. Also, suppose we have the following hypotheses:

(i) $F(X \times X) \subset g(X)$.

(ii) $g(X)$ is a complete subspace of $X$ with respect to the quasi-partial metric $q_{1}$. 
Then the mappings $F$ and $g$ have a coincidence point $(x, y)$ satisfying $g x=F(x, y)=F(y, x)=$ gy.

Moreover, if $F$ and $g$ are $w$-compatible, then $F$ and $g$ have a unique common coupled fixed point of the form $(u, u)$.

Remark 2.4 If we take $q_{1}(x, y)=q_{2}(x, y)$ for all $x, y \in X$, then Corollary 2.4 is reduced to Corollary 2.3 of Shatanawi and Pitea [38].

Corollary 2.5 Let $q_{1}$ and $q_{2}$ be two quasi-metrics on $X$ such that $q_{2}(x, y) \leq q_{1}(x, y)$, for all $x, y \in X$, and $F: X \times X \rightarrow X, g: X \rightarrow X$ be two mappings. Suppose that there exists $k \in[0,1)$ such that the condition

$$
q_{1}(F(x, y), F(u, v))+q(F(y, x), F(v, u)) \leq k\left[q_{2}(g u, F(u, v))+q_{2}(g v, F(v, u))\right]
$$

holds for all $x, y, u, v \in X$. Also, suppose we have the following hypotheses:

(i) $F(X \times X) \subset g(X)$.

(ii) $g(X)$ is a complete subspace of $X$ with respect to the quasi-partial metric $q_{1}$.

Then the mappings $F$ and $g$ have a coincidence point $(x, y)$ satisfying $g x=F(x, y)=F(y, x)=$ gy.

Moreover, if $F$ and $g$ are $w$-compatible, then $F$ and $g$ have a unique common coupled fixed point of the form $(u, u)$.

Remark 2.5 If we take $q_{1}(x, y)=q_{2}(x, y)$ for all $x, y \in X$, then Corollary 2.5 is reduced to Corollary 2.4 of Shatanawi and Pitea [38].

Corollary 2.6 Let $q_{1}$ and $q_{2}$ be two quasi-metrics on $X$ such that $q_{2}(x, y) \leq q_{1}(x, y)$, for all $x, y \in X$, and $F: X \times X \rightarrow X, g: X \rightarrow X$ be two mappings. Suppose that there exists $k \in\left[0, \frac{1}{2}\right)$ such that the condition

$$
q_{1}(F(x, y), F(u, v))+q(F(y, x), F(v, u)) \leq k\left[q_{2}(g x, F(u, v))+q_{2}(g y, F(v, u))\right]
$$

holds for all $x, y, u, v \in X$. Also, suppose we have the following hypotheses:

(i) $F(X \times X) \subset g(X)$.

(ii) $g(X)$ is a complete subspace of $X$ with respect to the quasi-partial metric $q_{1}$.

Then the mappings $F$ and $g$ have a coincidence point $(x, y)$ satisfying $g x=F(x, y)=F(y, x)=$ gy.

Moreover, if $F$ and $g$ are $w$-compatible, then $F$ and $g$ have a unique common coupled fixed point of the form $(u, u)$.

Corollary 2.7 Let $q_{1}$ and $q_{2}$ be two quasi-metrics on $X$ such that $q_{2}(x, y) \leq q_{1}(x, y)$, for all $x, y \in X$, and $F: X \times X \rightarrow X, g: X \rightarrow X$ be two mappings. Suppose that there exists $k \in[0,1)$ such that the condition

$$
q_{1}(F(x, y), F(u, v))+q(F(y, x), F(v, u)) \leq k\left[q_{2}(g u, F(x, y))+q_{2}(g v, F(y, x))\right]
$$


holds for all $x, y, u, v \in X$. Also, suppose we have the following hypotheses:

(i) $F(X \times X) \subset g(X)$.

(ii) $g(X)$ is a complete subspace of $X$ with respect to the quasi-partial metric $q_{1}$.

Then the mappings $F$ and $g$ have a coincidence point $(x, y)$ satisfying $g x=F(x, y)=F(y, x)=$ $g y$.

Moreover, if $F$ and $g$ are $w$-compatible, then $F$ and $g$ have a unique common coupled fixed point of the form $(u, u)$.

Let $g=I_{X}$ (the identity mapping) in Theorem 2.1 and Corollaries 2.1-2.7. Then we have the following results.

Corollary 2.8 Let $q_{1}$ and $q_{2}$ be two quasi-metrics on $X$ such that $q_{2}(x, y) \leq q_{1}(x, y)$, for all $x, y \in X$, and $F: X \times X \rightarrow X$ be a mapping. Suppose that there exist $k_{1}, k_{2}, k_{3}, k_{4}$, and $k_{5}$ in $[0,1)$ with $k_{1}+k_{2}+k_{3}+2 k_{4}+k_{5}<1$ such that the condition

$$
\begin{aligned}
& q_{1}(F(x, y), F(u, v))+q_{1}(F(y, x), F(v, u)) \\
& \leq k_{1}\left[q_{2}(x, u)+q_{2}(y, v)\right]+k_{2}\left[q_{2}(x, F(x, y))+q_{2}(y, F(y, x))\right] \\
&+k_{3}\left[q_{2}(u, F(u, v))+q_{2}(v, F(v, u))\right]+k_{4}\left[q_{2}(x, F(u, v))+q_{2}(y, F(v, u))\right] \\
&+k_{5}\left[q_{2}(u, F(x, y))+q_{2}(v, F(y, x))\right]
\end{aligned}
$$

holds for all $x, y, u, v \in X$. If $\left(X, q_{1}\right)$ is a complete quasi-partial metric space, then the mapping $F$ has a unique coupled fixed point of the form $(u, u)$.

Corollary 2.9 Let $(X, q)$ be a complete quasi-partial metric space, $F: X \times X \rightarrow X$ be a mapping. Suppose that there exist $k_{1}, k_{2}, k_{3}, k_{4}$, and $k_{5}$ in $[0,1)$ with $k_{1}+k_{2}+k_{3}+2 k_{4}+k_{5}<1$ such that the condition

$$
\begin{aligned}
& q(F(x, y), F(u, v))+q(F(y, x), F(v, u)) \\
& \leq k_{1}[q(x, u)+q(y, v)]+k_{2}[q(x, F(x, y))+q(y, F(y, x))] \\
&+k_{3}[q(u, F(u, v))+q(v, F(v, u))]+k_{4}[q(x, F(u, v))+q(y, F(v, u))] \\
&+k_{5}[q(u, F(x, y))+q(v, F(y, x))]
\end{aligned}
$$

holds for all $x, y, u, v \in X$. Then $F$ has a unique coupled fixed point of the form $(u, u)$.

Remark 2.6 Corollary 2.9 improve and extend Corollary 2.5 of Shatanawi and Pitea [38], the contractive condition is replaced by the new contractive condition defined by (2.35).

Corollary 2.10 Let $q_{1}$ and $q_{2}$ be two quasi-metrics on $X$ such that $q_{2}(x, y) \leq q_{1}(x, y)$, for all $x, y \in X$, and $F: X \times X \rightarrow X$ be a mapping. Suppose that there exist $a_{i} \in[0,1)(i=$ $1,2,3, \ldots, 10)$ with

$$
a_{1}+a_{2}+a_{3}+a_{4}+a_{5}+a_{6}+2\left(a_{7}+a_{8}\right)+a_{9}+a_{10}<1
$$


such that the condition

$$
\begin{aligned}
q_{1}( & (x, y), F(u, v)) \\
\leq & a_{1} q_{2}(x, u)+a_{2} q_{2}(y, v)+a_{3} q_{2}(x, F(x, y))+a_{4} q_{2}(y, F(y, x)) \\
& +a_{5} q_{2}(u, F(u, v))+a_{6} q_{2}(v, F(v, u))+a_{7} q_{2}(x, F(u, v))+a_{8} q_{2}(y, F(v, u)) \\
& +a_{9} q_{2}(u, F(x, y))+a_{10} q_{2}(v, F(y, x))
\end{aligned}
$$

holds for all $x, y, u, v \in X$. If $\left(X, q_{1}\right)$ is a complete quasi-partial metric space. Then the mapping $F$ has a unique coupled fixed point of the form $(u, u)$.

\section{Remark 2.7}

(1) If we take $q_{1}(x, y)=q_{2}(x, y)$ for all $x, y \in X$ and $a_{7}=a_{8}=a_{9}=a_{10}=0$, then Corollary 2.10 is reduced to Corollary 2.6 of Shatanawi and Pitea [38].

(2) If we take $q_{1}(x, y)=q_{2}(x, y)$ for all $x, y \in X$ and $a_{i}=0(i=3,4,5, \ldots, 10)$, then Corollary 2.10 extends Theorem 2.1 of Aydi [12] on the class of quasi-partial metric spaces.

(3) If we take $q_{1}(x, y)=q_{2}(x, y)$ for all $x, y \in X, a_{1}=a_{2}$ and $a_{i}=0(i=3,4,5, \ldots, 10)$, then Corollary 2.10 extends the Corollary 2.2 of Aydi [12] on the class of quasi-partial metric spaces.

(4) If we take $q_{1}(x, y)=q_{2}(x, y)$ for all $x, y \in X$ and $a_{i}=0(i=1,2,4,6,7,8,9,10)$, then Corollary 2.10 extends Theorem 2.4 of Aydi [12] on the class of quasi-partial metric spaces.

(5) If we take $q_{1}(x, y)=q_{2}(x, y)$ for all $x, y \in X$ and $a_{i}=0(i=1,2,3,4,5,6,8,10)$, then Corollary 2.10 extends Theorem 2.5 of Aydi [12] on the class of quasi-partial metric spaces.

(6) If we take $q_{1}(x, y)=q_{2}(x, y)$ for all $x, y \in X, a_{3}=a_{9}$ and $a_{i}=0(i=1,2,4,5,6,7,8,10)$, then Corollary 2.10 extends Corollary 2.6 of Aydi [12] on the class of quasi-partial metric spaces.

(7) If we take $q_{1}(x, y)=q_{2}(x, y)$ for all $x, y \in X, a_{7}=a_{9}$ and $a_{i}=0(i=1,2,3,4,5,6,8,10)$, then Corollary 2.10 extends Corollary 2.7 of Aydi [12] on the class of quasi-partial metric spaces.

Corollary 2.11 Let $q_{1}$ and $q_{2}$ be two quasi-metrics on $X$ such that $q_{2}(x, y) \leq q_{1}(x, y)$, for all $x, y \in X$, and $F: X \times X \rightarrow X$ be a mapping. Suppose that there exists $k \in[0,1)$ such that the condition

$$
q_{1}(F(x, y), F(u, v))+q(F(y, x), F(v, u)) \leq k\left[q_{2}(x, u)+q_{2}(y, v)\right]
$$

holds for all $x, y, u, v \in X$. If $\left(X, q_{1}\right)$ is a complete quasi-partial metric space. Then the mapping $F$ has a unique coupled fixed point of the form $(u, u)$.

Remark 2.8 If we take $q_{1}(x, y)=q_{2}(x, y)$ for all $x, y \in X$, then Corollary 2.11 is reduced to Corollary 2.7 of Shatanawi and Pitea [38].

Corollary 2.12 Let $q_{1}$ and $q_{2}$ be two quasi-metrics on $X$ such that $q_{2}(x, y) \leq q_{1}(x, y)$, for all $x, y \in X$, and $F: X \times X \rightarrow X$ be a mapping. Suppose that there exists $k \in[0,1)$ such that the 
condition

$$
q_{1}(F(x, y), F(u, v))+q(F(y, x), F(v, u)) \leq k\left[q_{2}(x, F(x, y))+q_{2}(y, F(y, x))\right]
$$

holds for all $x, y, u, v \in X$. If $\left(X, q_{1}\right)$ is a complete quasi-partial metric space, then the mapping $F$ has a unique coupled fixed point of the form $(u, u)$.

Remark 2.9 If we take $q_{1}(x, y)=q_{2}(x, y)$ for all $x, y \in X$, then Corollary 2.12 is reduced to Corollary 2.8 of Shatanawi and Pitea [38].

Corollary 2.13 Let $q_{1}$ and $q_{2}$ be two quasi-metrics on $X$ such that $q_{2}(x, y) \leq q_{1}(x, y)$, for all $x, y \in X$, and $F: X \times X \rightarrow X$ be a mapping. Suppose that there exists $k \in[0,1)$ such that the condition

$$
q_{1}(F(x, y), F(u, v))+q(F(y, x), F(v, u)) \leq k\left[q_{2}(u, F(u, v))+q_{2}(v, F(v, u))\right]
$$

holds for all $x, y, u, v \in X$. If $\left(X, q_{1}\right)$ is a complete quasi-partial metric space, then the mapping $F$ has a unique coupled fixed point of the form $(u, u)$.

Remark 2.10 If we take $q_{1}(x, y)=q_{2}(x, y)$ for all $x, y \in X$, then Corollary 2.13 is reduced to Corollary 2.9 of Shatanawi and Pitea [38].

Corollary 2.14 Let $q_{1}$ and $q_{2}$ be two quasi-metrics on $X$ such that $q_{2}(x, y) \leq q_{1}(x, y)$, for all $x, y \in X$, and $F: X \times X \rightarrow X$ be a mapping. Suppose that there exists $k \in\left[0, \frac{1}{2}\right)$ such that the condition

$$
q_{1}(F(x, y), F(u, v))+q(F(y, x), F(v, u)) \leq k\left[q_{2}(x, F(u, v))+q_{2}(y, F(v, u))\right]
$$

holds for all $x, y, u, v \in X$. If $\left(X, q_{1}\right)$ is a complete quasi-partial metric space, then the mapping $F$ has a unique coupled fixed point of the form $(u, u)$.

Corollary 2.15 Let $q_{1}$ and $q_{2}$ be two quasi-metrics on $X$ such that $q_{2}(x, y) \leq q_{1}(x, y)$, for all $x, y \in X$, and $F: X \times X \rightarrow X$ be a mapping. Suppose that there exists $k \in[0,1)$ such that the condition

$$
q_{1}(F(x, y), F(u, v))+q(F(y, x), F(v, u)) \leq k\left[q_{2}(u, F(x, y))+q_{2}(v, F(y, x))\right]
$$

holds for all $x, y, u, v \in X$. If $\left(X, q_{1}\right)$ is a complete quasi-partial metric space, then the mapping $F$ has a unique coupled fixed point of the form $(u, u)$.

Now, we introduce an example to support our results.

Example 2.1 Let $X=[0,1]$, and two quasi-partial metrics $q_{1}, q_{2}$ on $X$ be given as

$$
q_{1}(x, y)=|x-y|+x \quad \text { and } \quad q_{2}(x, y)=\frac{1}{2}(|x-y|+x)
$$


for all $x, y \in X$. Also, define $F: X \times X \rightarrow X$ and $g: X \rightarrow X$ as

$$
F(x, y)=\frac{x+y}{16} \text { and } g x=\frac{x}{2}
$$

for all $x, y \in X$. Then

(1) $\left(X, q_{1}\right)$ is a complete quasi-partial metric space.

(2) $F(X \times X) \subset X$.

(3) $F$ and $g$ is $w$-compatible.

(4) For any $x, y, u, v \in X$, we have

$$
q_{1}(F(x, y), F(u, v))+q_{1}(F(y, x)+F(v, u)) \leq \frac{1}{2}\left(q_{2}(g x, g u)+q_{2}(g y, g v)\right) .
$$

Proof The proofs of (1), (2), and (3) are clear. Next we show that (4). In fact, for $x, y, u, v \in X$, we have

$$
\begin{aligned}
q_{1} & (F(x, y), F(u, v))+q_{1}(F(y, x)+F(v, u)) \\
\quad & =q_{1}\left(\frac{x+y}{16}, \frac{u+v}{16}\right)+q_{1}\left(\frac{y+x}{16}, \frac{v+u}{16}\right) \\
& =\frac{1}{8}(|x+y-(u+v)|+(x+y)) \\
& =\frac{1}{4}\left(\left|\frac{1}{2}(x+y)-\frac{1}{2}(u+v)\right|+\frac{1}{2}(x+y)\right) \\
& \leq \frac{1}{4}\left(\left|\frac{1}{2} x-\frac{1}{2} u\right|+\frac{1}{2} x+\left|\frac{1}{2} y-\frac{1}{2} v\right|+\frac{1}{2} y\right) \\
& =\frac{1}{2}\left(q_{2}(g x, g u)+q_{2}(g y, g v)\right) .
\end{aligned}
$$

Thus, $F$ and $g$ satisfy all the hypotheses of Corollary 2.3. So, $F$ and $g$ have a unique common coupled fixed point. Here $(0,0)$ is the unique common coupled fixed point of $F$ and $g$.

\section{Competing interests}

The authors declare that they have no competing interests.

\section{Authors' contributions}

Both authors contributed equally to this work. Both authors read and approved the final manuscript.

\section{Author details}

${ }^{1}$ Institute of Applied Mathematics and Department of Mathematics, Hangzhou Normal University, Hangzhou, Zhejiang 310036, China. ${ }^{2}$ College of Statistics and Mathematics, Yunnan University of Finance and Economics, Kunming, Yunnan 650221 , China.

\section{Acknowledgements}

This work is supported by the National Natural Science Foundation of China $(11271105,11361070)$, the Natural Science Foundation of Zhejiang Province (Y6110287, LY12A01030), and the Natural Science Foundation of Shandong Province (ZR2013AL015).

Received: 21 November 2013 Accepted: 30 December 2013 Published: 22 Jan 2014

\section{References}

1. Matthews, SG: Partial metric topology. In: General Topology and Its Applications. Proc. 8th Summer Conf. Queen's College, 1992, vol. 728, pp. 183-197. Ann. New York Acad. Sci., New York (1994) 
2. Abdeljawad, T, Karapınar, E, Taş, K: Existence and uniqueness of a common fixed point on partial metric spaces. Appl. Math. Lett. 24(11), 1900-1904 (2011)

3. Abdeljawad, T, Karapınar, E, Taş, K: A generalized contraction principle with control functions on partial metric spaces. Comput. Math. Appl. 63(3), 716-719 (2012)

4. Abdeljawad, T: Fixed points and generalized weakly contractive mappings in partial metric spaces. Math. Comput. Model. 54(11-12), 2923-2927 (2011)

5. Altun, I, Acar, Ö: Fixed point theorems for weak contractions in the sense of Berinde on partial metric spaces. Topol. Appl. 159, 2642-2648 (2012)

6. Altun, I, Erduran, A: Fixed point theorems for monotone mappings on partial metric spaces. Fixed Point Theory Appl. 2011, Article ID 508730 (2011). doi:10.1155/2011/508730

7. Altun, I, Simsek, H: Some fixed point theorems on dualistic partial metric spaces. J. Adv. Math. Stud. 1(1-2), 1-8 (2008)

8. Altun, I, Sola, F, Simsek, H: Generalized contractions on partial metric spaces. Topol. Appl. 157(18), 2778-2785 (2010)

9. Altun, I, Sadarangani, K: Corrigendum to 'Generalized contractions on partial metric spaces' [Topology Appl. 157(18), 2778-2785 (2010)]. Topol. Appl. 158(13), 1738-1740 (2011)

10. Amiri, P, Rezapour, S: Fixed point of multi-valued operators on partial metric spaces. Anal. Theory Appl. 29(2), 158-168 (2013). doi:10.4208/ata.2013.v29.n2.7

11. Aydi, H: Some fixed point results in ordered partial metric spaces. J. Nonlinear Sci. Appl. 4(2), 1-12 (2011)

12. Aydi, H: Some coupled fixed point results on partial metric spaces. Int. J. Math. Sci. 2011, Article ID 647091 (2011)

13. Aydi, $\mathrm{H}$ : Fixed point theorems for generalized weakly contractive in ordered partial metric spaces. J. Nonlinear Anal. Optim., Theory Appl. 2(2), 269-284 (2011)

14. Aydi, H, Karapınar, E, Shatanawi, W: Coupled fixed point results for $(\psi, \varphi)$-weakly contractive condition in ordered partial metric spaces. Comput. Math. Appl. 62, 4449-4460 (2011)

15. Bari, CD, Milojević, M, Radenović, S, Vetro, P: Common fixed points for self-mappings on partial metric spaces. Fixed Point Theory Appl. 2012, Article ID 140 (2012). doi:10.1186/1687-1812-2012-140

16. Klin-eam, C: Modified proof of Caristi's fixed point theorem on partial metric spaces. J. Inequal. Appl. 2013, Article ID 210 (2013). doi:10.1186/1029-242X-2013-210

17. Chen, C, Zhu, C: Fixed point theorems for weakly C-contractive mappings in partial metric spaces. Fixed Point Theory Appl. 2013, Article ID 107 (2013). doi:10.1186/1687-1812-2013-107

18. Ćirić, L, Samet, B, Aydi, H, Vetro, C: Common fixed point results of generalized contractions on partial metric spaces and application. Appl. Math. Comput. 218, 2398-2406 (2011)

19. Golubović, Z, Kadelburg, Z, Radenović, S: Coupled coincidence points of mappings in ordered partial metric spaces Abstr. Appl. Anal. 2012, Article ID 192581 (2012). doi:10.1155/2012/192581

20. Karapınar, E, Erhan, I: Fixed point theorems for operators on partial metric spaces. Appl. Math. Lett. 24, 1894-1899 (2011)

21. Nashine, HK, Kadelburg, Z, Radenović, S: Common fixed point theorems for weakly isotone increasing mappings in ordered partial metric spaces. Math. Comput. Model. 57, 2355-2365 (2013)

22. Oltra, S, Valero, O: Banach's fixed point theorem for partial metric spaces. Rend. Ist. Mat. Univ. Trieste 36(1-2), 17-26 (2004)

23. Romaguera, S: A Kirk type characterization of completeness for partial metric spaces. Fixed Point Theory Appl. 2010 Article ID 493298 (2010). doi:10.1155/2010/493298

24. Romaguera, S: Fixed point theorems for generalized contractions on partial metric spaces. Topol. Appl. 159, 194-199 (2010)

25. Samet, B, Rajović, M, Lazović, R, Stoijković, R: Common fixed point results for nonlinear contractions in ordered partial metric spaces. Fixed Point Theory Appl. 2011, Article ID 71 (2011). doi:10.1186/1687-1812-2011-71

26. Shatanawi, W, Nashine, HK: A generalization of Banach's contraction principle of nonlinear contraction in a partial metric spaces. J. Nonlinear Sci. Appl. 5, 37-43 (2012)

27. Shatanawi, W, Nashine, HK, Tahat, N: Generalization of some coupled fixed point results on partial metric spaces. Int. J. Math. Math. Sci. 2012, Article ID 686801 (2012)

28. Shatanawi, W, Samet, B, Abbas, M: Coupled fixed point theorems for mixed monotone mappings in ordered partial metric spaces. Math. Comput. Model. 55, 680-687 (2012)

29. Shatanawi, W, Postolache, M: Coincidence and fixed point results for generalized weak contractions in the sense of Berinde on partial metric spaces. Fixed Point Theory Appl. 2013, Article ID 54 (2013). doi:10.1186/1687-1812-2013-54

30. Radenović, S: Remarks on some coupled fixed point results in partial metric spaces. Nonlinear Funct. Anal. Appl. 18(1), 39-50 (2013)

31. Nashine, HK, Kadelburg, Z, Radenović, S: Fixed point theorems via various cyclic contractive conditions in partial metric spaces. Publ. Inst. Math. 93(107), 69-93 (2013)

32. Valero, O: On Banach fixed point theorems for partial metric spaces. Appl. Gen. Topol. 6(2), 229-240 (2005)

33. Haghi, RH, Rezapour, S, Shahzad, N: Be careful on partial metric fixed point results. Topol. Appl. 160, 450-454 (2013)

34. Karapınar, E, Erhan, I, Öztürk, A: Fixed point theorems on quasi-partial metric spaces. Math. Comput. Model. 57, 2442-2448 (2013). doi:10.1016/j.mcm.2012.06.036

35. Bhaskar, TG, Lakshmikantham, V: Fixed point theorems in partially ordered metric spaces and applications. Nonlinear Anal. 65, 1379-1393 (2006)

36. Lakshmikantham, V, Ćirić, L: Coupled fixed point theorems for nonlinear contractions in partially ordered metric spaces. Nonlinear Anal. 70, 4341-4349 (2009)

37. Abbas, M, Khan, MA, Radenović, S: Common coupled fixed point theorem in cone metric space for $w$-compatible mappings. Appl. Math. Comput. 217, 195-202 (2010). doi:10.1016/j.amc.2010.05.042

38. Shatanawi, W, Pitea, A: Some coupled fixed point theorems in quasi-partial metric spaces. Fixed Point Theory Appl. 2013, Article ID 153 (2013). doi:10.1186/1687-1812-2013-153

39. Abbas, M, Khan, AR, Nazir, T: Coupled common fixed point results in two generalized metric spaces. Appl. Math Comput. 217, 6328-6336 (2011). doi:10.1016/j.amc.2011.01.006

40. Abbas, M, Nazir, T, Radenović, S: Common fixed point of generalized weakly contractive maps in partially ordered G-metric spaces. Appl. Math. Comput. 218(18), 9383-9395 (2012) 
41. Abbas, M, Sintunavarat, W, Kumam, P: Coupled fixed point of generalized contractive mappings on partially ordered G-metric spaces. Fixed Point Theory Appl. 2012, Article ID 31 (2012). doi:10.1186/1687-1812-2012-31

42. Altun, I, Simsek, H: Some fixed point theorems on ordered metric spaces and application. Fixed Point Theory Appl. 2010, Article ID 621469 (2010). doi:10.1155/2010/621469

43. Aydi, H, Damjanović, B, Samet, B, Shatanawi, W: Coupled fixed point theorems for nonlinear contractions in partially ordered G-metric spaces. Math. Comput. Model. 54(9-10), 2443-2450 (2011)

44. Aydi, H, Postolache, M, Shatanawi, W: Coupled fixed point results for $(\psi, \varphi)$-weakly contractive mappings in ordered G-metric spaces. Comput. Math. Appl. 63(1), 298-309 (2012)

45. Cho, YJ, Rhoades, BE, Saadati, R, Samet, B, Shatanawi, W: Nonlinear coupled fixed point theorems in ordered generalized metric spaces with integral type. Fixed Point Theory Appl. 2012, Article ID 8 (2012). doi:10.1186/1687-1812-2012-8

46. Choudhury, BS, Maity, P: Coupled fixed point results in generalized partially ordered G-metric spaces. Math. Comput. Model. 54, 73-79 (2011)

47. Choudhury, BS, Metiya, N, Postolache, M: A generalized weak contraction principle with applications to coupled coincidence point problems. Fixed Point Theory Appl. 2013, Article ID 152 (2013). doi:10.1186/1687-1812-2013-152

48. Gu, F, Yin, Y: A new common coupled fixed point theorem in generalized metric space and applications to integral equations. Fixed Point Theory Appl. 2013, Article ID 266 (2013). doi:10.1186/1687-1812-2013-266

49. Gu, F, Zhou, S: Coupled common fixed point theorems for a pair of commuting mappings in partially ordered G-metric spaces. Fixed Point Theory Appl. 2013, Article ID 64 (2013). doi:10.1186/1687-1812-2013-64

50. Hong, S: Fixed points of multivalued operators in ordered metric spaces with applications. Nonlinear Anal. 72(11), 3929-3942 (2010). doi:10.1016/j.na.2010.01.013

51. Karapınar, E: Coupled fixed point theorems for nonlinear contractions in cone metric spaces. Comput. Math. Appl. 59, 3656-3668 (2010)

52. Luong, NV, Thuan, NX: Coupled fixed point theorems in partially ordered G-metric spaces. Math. Comput. Model. 55(3-4), 1601-1609 (2012)

53. Mustafa, Z, Aydi, H, Karapınar, E: Mixed g-monotone property and quadruple fixed point theorems in partially ordered metric space. Fixed Point Theory Appl. 2012, Article ID 71 (2012). doi:10.1186/1687-1812-2012-71

54. Qiu, Z, Hong, S: Coupled fixed points for multivalued mappings in fuzzy metric spaces. Fixed Point Theory Appl. 2013 Article ID 162 (2013). doi:10.1186/1687-1812-2013-162

55. Samet, B: Coupled fixed point theorems for a generalized Meir-Keeler contraction in partially ordered metric spaces. Nonlinear Anal. 72, 4508-4517 (2010)

56. Saadati, R, Vaezpour, SM, Vetro, P, Rhoades, BE: Fixed point theorems in generalized partially ordered G-metric spaces. Math. Comput. Model. 52(5-6), 797-810 (2010)

57. Sabetghadam, F, Masiha, HP, Sanatpour, AH: Some coupled fixed point theorems in cone metric spaces. Fixed Point Theory Appl. 2009, Article ID 125426 (2009). doi:10.1155/2009/125426

58. Sedghi, S, Altun, I, Shobe, N: Coupled fixed point theorems for contractions in fuzzy metric spaces. Nonlinear Anal. 72, 1298-1304 (2010)

59. Shatanawi, W: On $w$-compatible mappings and common coupled coincidence point in cone metric spaces. Appl. Math. Lett. 25, 925-931 (2012)

60. Shatanawi, W: Fixed point theorems for nonlinear weakly C-contractive mappings in metric spaces. Math. Comput. Model. 54(11-12), 2816-2826 (2011)

61. Shatanawi, W, Abbas, M, Nazir, T: Common coupled coincidence and coupled fixed point results in two generalized metric spaces. Fixed Point Theory Appl. 2011, Article ID 80 (2011). doi:10.1186/1687-1812-2011-80

62. Shatanawi, W, Samet, B, Abbas, M: Coupled fixed point theorems for mixed monotone mappings in ordered partial metric spaces. Math. Comput. Model. 55, 680-687 (2012)

10.1186/1687-1812-2014-19

Cite this article as: Gu and Wang: Some coupled fixed-point theorems in two quasi-partial metric spaces. Fixed Point Theory and Applications 2014, 2014:19

\section{Submit your manuscript to a SpringerOpen ${ }^{\ominus}$ journal and benefit from:}

- Convenient online submission

- Rigorous peer review

- Immediate publication on acceptance

- Open access: articles freely available online

- High visibility within the field

- Retaining the copyright to your article

Submit your next manuscript at $>$ springeropen.com 